\title{
Optimization of responses in electron beam welding of inconel-718 alloy using genetic algorithm approach
}

\author{
Vishnu $\mathbf{S}^{1^{*}}$, Satheesh $\mathbf{M}^{2}$, Edwin Raja Dhas ${ }^{2}$ and Ramanan $\mathbf{G}^{3}$ \\ Research Scholar, Department of Mechanical Engineering, Noorul Islam Centre for Higher Education, Kumaracoil, \\ India $^{1}$ \\ Professor, Department Mechanical Engineering, Noorul Islam Centre for Higher Education, Kumaracoil, India ${ }^{2}$ \\ Associate Professor, Department Aeronautical Engineering, ACS College of Engineering, Bangalore, India ${ }^{3}$
}

Received: 04-August-2021; Revised: 17-November-2021; Accepted: 19-November-2021

(C)2021 Vishnu S et al. This is an open access article distributed under the Creative Commons Attribution (CC BY) License, which permits unrestricted use, distribution, and reproduction in any medium, provided the original work is properly cited.

\begin{abstract}
A good quality in Electron Beam Welding $(E B W)$ process is obtained by optimizing the process parameters because evolutionary techniques like Genetic Algorithm (GA) play an important role in deciding the weld parameters. In this work an attempt made for multi objective optimization task with the use of genetic algorithm for Inconel 718 alloy material using the $\mathrm{EB} W$ process. The desired weld quality is determined on the basis of the welding input parameters, and the experiments are conducted based on Response Surface Methodology (RSM). From study welding current (Iw); focus current (If) and the speed (s) are selected as the input parameters. Depth of penetration (DP) and Bead width (BW) were selected as output response for quality targets. The experimental results indicated that bead width 4.8 and depth of penetration 7.6 for the optimum values at $70 \mathrm{~mA}, 530 \mathrm{~mA}$, and $23 \mathrm{~mm} / \mathrm{s}$ respectively. Grey Relational Analysis (GRA) was used for the optimization of the input parameter concurrently with the consideration of the two responses. Analysis of variance (ANOVA) method was utilized in the assessment of the importance of factors on the overall weld quality. The optimal welding parameters for minimum Bead width were found to be Iw1If3S2 and for maximum Depth of Penetration was Iw2If3S1. The outcomes of this work is compared for proposed GRA and GA algorithms by precision and welding speed and are explained. The metallurgical characteristics validate the outcome of the response characteristics for best grade value.
\end{abstract}

\section{Keywords}

Inconel718 alloy, Electron beam welding, Optimization technique, Grey relational analysis, Genetic algorithm.

\section{Introduction}

Inconel 718 alloy is a chromium-titanium-nickelbased austenitic alloy with increased strength and better resistance to carburization and oxidation at increased temperatures. This is an important and efficient alloy material for the power plants of next generation [1]. These alloys can be used in sea water, power plant applications with temperature ranges up to $900^{\circ} \mathrm{C}$. The combination of resistance and the improved mechanical property makes this alloy useful in case of various applications, such as exposure of long-term and higher temperatures in corrosive area. High temperature tubes of heat exchanger in gas-cooled nuclear reactors and super heater tubes are the other applications of Inconel 718 alloy [2]. In addition, Electron Beam Welding (EBW) process is a metal fabrication technique in the presence of multi-factors and multi-objectives.

*Author for correspondence

1501
This connection of normal metals, like aluminium, steel, and magnesium of $1 \mathrm{~mm}$ to $6 \mathrm{~mm}$ thickness in almost all positions can be done using this process [3]. The weld joint quality highly depends on the parameters of the input process and the control of this input process parameter acts as a basic problem to the manufacturer in obtaining increased weld quality in welded joint [4]. Highly skilled engineers or operators select the parameters depending on trial and error method in order to produce a welded joint with necessary indications, but the selection of parameters using this method was time consuming [5]. The welds are utilized to find, whether they are suitable to meet the all the required specification [6]. Many researchers have studied the effect of mechanical properties of Inconel-718 alloy material and few authors published about fabrication, solidification and characterization of these alloys. It is understood that there is lack of papers on the effect of electron beam welding parameters and with their responses of 
bead width and depth of penetration with quality optimization. Previous literature study [1-6] states that Design of Experiments (DOE) is helpful tool to optimize welding processes but this method affects the weld quality. So this research work is planned to conduct using Response Surface Methodology (RSM) tool to model and conduct the experiments to predict the strength of welding material with bead width and depth of penetration. The objective of this research work to optimize the weld qualities from EBW. The outcomes of this work are compared for proposed Grey Relational Analysis (GRA) and Genetic (GA) algorithms. A best grade level welding parameters can be utilized to validate the Inconel 718 alloy components and the same level can be utilized in Aerospace and Automobile Industries. Later these optimization results can be used as a reference to predict the quality of weld with response parameters after EBW.

\section{Literature review}

In recent years, the evolutionary algorithms, experiment design and the model coding are commonly utilized in the development of the mathematical relations among the input parameters of the welding process and the output variables of the weld joint. The extreme competitiveness in the market is forcing manufactures to revise their advanced manufacturing processes, ensuing in the redesign of industrial machine and mechanical components to avoid costly fabrication and machining processes. Halsey et al. presented RSM method was used to optimize of voltage, current, and the welding speed of process parameter in order to find the maximum penetration depth on fusion manufacturing [7].

Bal et al. [8] studied the response effects on welding strength were analyzed for the optimized welding are of EBW by the use of GRA.

Choudhury and Chandrasekaran [9] discussed the governing equations for the pulsed EBW welding of lightweight materials were developed in which has given a conclusion that the developed mathematical relations can be used easily in the form of a program in automated welding, to obtain the required response data.

Shrivastava et al. [10] studied the input points that are optimized to enhance the mechanical properties associated with the joints of Inconel 718 alloy using Particle Swarm Optimization (PSO).
Vagheesan and Govindarajalu [11] presented the experiments were carried out based on neural network-genetic algorithm for the optimization.

Ramanan and Dhas [12] studied grey relational optimization for different input parameters of aluminium alloy material. It was concluded that the increased heat input produced very less output rate.

Ghosh et al. [13] presented the parameters of the pulsed EBW were optimized with the use of GRA in order to obtain maximum Ultimate Tensile Strength (UTS) on magnesium alloy. The electron beam welding process optimization was done in for the optimal combination of parameters to produce desired elongation and tensile strength with the optimal design analysis.

Sokkalingam et al. [14] studied the electron beam input data of stainless steel joints were optimized using the ANN and provided a conclusion that the maximum heat and ideal time are responsible for sound quality joints.

Taguchijeve and FSW [15] studied that the optimization of the parameters of advanced welding process is done using GRA to produce the desired quality of weldments.

It is clear that very few researches are performed in the characterization and the optimization of Inconel 718 alloy. Many researchers have studied the effect of mechanical properties of Inconel-718 alloy material and few others published about fabrication, solidification of these alloys. It is understood that there is lack of papers on the effect of electron beam welding parameters and with their responses of bead width and depth of penetration. Previous literature study states that DOE is helpful tool to optimize welding processes and it affects the weld quality. So this work is planned to conduct using RSM tool to model and conduct the experiments to predict the strength of welding material with bead width and depth of penetration. Also the objective of this work is the multi-objective optimization using GRA to optimize the parameters of EBW process, where the bead width and the depth of penetration act as the output response. With the analysis of grey relational grade, the determination of the important parameter was carried out. ANOVA method was used in the determination of the impact of individual factors. In addition, experimental and optimized results were validated using the microstructure fractography. 


\section{Materials and methods}

An Inconel 718 alloy plates of dimension $100 \times 50 \times$ $6 \mathrm{~mm}$ was butt welded by EBW weld machine. Table 1 illustrates the composition of the base material. In this alloy Nickel has more percentage and that in increasing the strength and corrosion resistance material. Welding current, focus current and welding speed are considered as the input process parameters [16]. Various trials were performed in order to choose the max level and min level of input value [17]. Based on the literatures study response surface method was chosen, and the experiments were carried out on the basis of RSM method. Since design of experiments optimises the experimental process but affects the weld quality [18].

In this study 27 number of experiments was conducted as per design of experiment. Table 2 illustrates the process parameter and their levels. The selected objective functions are the bead width and depth of penetration were measured. Based on the design experiments were performed, and all the experimental data are submitted in Table 3. The result from EBW varies for BW from 3.987 to 6.578 and for DP from 5.643 to 8.540 . Due to the variation in heat inputs has less effect on the mechanical properties. From EBW all the sample regions were cut by the weld sample, and with the use of various levels of emery sheet the welded specimens were polished by diamond polishing and alumina polishing to obtain $0.05 \mu \mathrm{m}$ finish [19]. The characteristics of the welding elements were obtained using the metallographic analyses, such as microstructure fractographic analysis. Non dominated Sorting Genetic Algorithm-II (NSGA-II) is the well-known approach that has been selected and implemented for this research work. The high relevancy of NSGA-II, it's easy to compute the factors together with its fast convergence property and maintain wide solutions suitable real-time optimization problems [20].

Table 1 Composition of the base metal

\begin{tabular}{llllllllll}
\hline Element & Ni & Ti & Si & Cr & Al & P & Nb & C & Mn \\
\hline Wt. $\%$ & 52 & 0.65 & 0.35 & 17 & 0.5 & 0.015 & 4.75 & 0.08 & 0.35 \\
\hline
\end{tabular}

Table 2 Input process factors and levels

\begin{tabular}{lllll}
\hline Parameters & Symbol & $\mathbf{1}$ & $\mathbf{2}$ & $\mathbf{3}$ \\
\hline Welding Current $(\mathrm{mA})$ & Iw & 60 & 70 & 80 \\
\hline Focus Current $(\mathrm{mA})$ & If & 525 & 530 & 535 \\
\hline Speed $(\mathrm{mm} / \mathrm{s})$ & S & 17 & 20 & 23 \\
\hline
\end{tabular}

3.1Grey relational analysis (GRA)

In the initial step, the original response values are transformed into response values, for which equation (1) was utilized. The successive tests were performed based on these grade values, and are depicted in Table 4. In GRA [21], the data are initially normalized, and using this normalized data, the evaluation of the coefficients is done.

3.1.1Generation of grey relational value Experimental value is grouped into lower is better than higher is better criterion. Higher-the-better is the direct data pre-processing methods for the BW used in this study, and is given in Equation 1.

$x_{i}(k)=\frac{\max y_{i}(k)-y_{i}(k)}{\max y_{i}(k)-\min y_{i}(k)}$

In the same way, lower the better is the normalized data processing for DP [22] and Equation 2 is given below.

$x_{i}(k)=\frac{y_{i}(k)-\min y_{i}(k)}{\max y_{i}(k)-\min y_{i}(k)}$ where, $\mathrm{n}$ is the number of factors, $\mathrm{y}_{\mathrm{i}}(\mathrm{k})$ is the sequence level, $\mathrm{y}_{\mathrm{i}} \times(\mathrm{k})$ is the data after generated; $\mathrm{i}=$ $1,2, \ldots . \mathrm{m} ; \mathrm{k}=1,2, \ldots . \mathrm{n} ; \mathrm{m}$ is the number of experimental data, min $y_{i}(k)$ is the minimum value of $\mathrm{y}_{\mathrm{i}}(\mathrm{k})$, and $\max \mathrm{y}_{\mathrm{i}}(\mathrm{k})$ is the maximum value of $\mathrm{y}_{\mathrm{i}}(\mathrm{k})$. Table 4 shows the normalized values [23].

3.1.2Grey relational coefficient (CRC)

The experimental value of coefficient is estimated using the relation given in Equation 3 as,

$$
\epsilon_{i}(k)=\frac{\Delta_{\min }-\varphi \Delta_{\max }}{\Delta_{0 i}+\varphi \Delta_{\max }}
$$

In equation $\Delta_{\mathrm{oi}}$ is the change in value among $\mathrm{y}_{\mathrm{o}}(\mathrm{k})$ and $\mathrm{y}_{\mathrm{i}}(\mathrm{k}), \mathrm{y}_{0}(\mathrm{k})$ is the ideal sequence, $\varepsilon_{\mathrm{i}}(\mathrm{k})$ indicates the grey relation coefficient, $\Delta \max$ is the highest value and $\Delta \min$ is lowest value.

3.1.3Grey relational grade

After data collection from GRC data the Grey Relational Grade (CRG) is estimated by given equation is calculated using the average of coefficient constant of all the observations, and is expresses as Equation 4,

$\gamma_{i}=\frac{1}{n} \sum_{k=1}^{n} \epsilon_{i}(k)$

From results, the grades indicate the level of response between position and comparative sequence. If this value is high for equivalent process parameter set on comparison with other, then it is found as the best possible setting [12]. 
Vishnu S et al.

\subsection{Proposed EBW optimization techniques}

GA is computerized algorithms with search and several optimization steps on the basis of the evolutionary process of biological organisms exist in nature. During the course of evolution, natural populations evolve based on the principles of survival of the fittest and the natural selection. For solving each cases variable $\mathrm{x}$ is typically encoded into a string or chromosome structure with a possible solution.

3.2.1Welding Parameter Optimization in EBW Using GA

Optimization by means of GA provides the optimal solution of input and output parameters in EBW process for Inconel 718 alloy. The three important factors to be considered while performing optimization are the

\section{Decision variables}

The three decision variables considered are, the welding current, focus current and welding speed that acts as the welding parameters.

\section{Objective functions}

One of the two objectives is the beam width and the other is the depth of penetration. The multi regression equations are considered as the objective functions for the alloy.

\section{Constraints}

The constraints that affect the optimal selection of welding conditions are taken into account.

$60 \leq \mathrm{Iw} \leq 80 ; 525 \leq \mathrm{If} \leq 535 ; 17 \leq \mathrm{S} \leq 23$
3.2.2Non dominated sorting genetic algorithm (NSGAII)

NSGA-II is the well-known approach that has been selected and implemented for this research work. The high relevancy of NSGA-II, it's easy to compute the factors together with its fast convergence property and maintain wide solutions suitable real-time optimization problems [20]. This algorithm is complex and can be explained using expression, which shows the objective rate, based on size of population and generations. In such a way, the expression time $\mathrm{T}$ needed for the development of the researching procedure is expressed by factors and all ignored aspects are covered through GA approach [21].

\section{Results}

EBW on Inconel 718 alloy was carried out based on response surface method to analyze the parameter effect on the response of outputs of welding process, by terms of bead width and depth of penetration. The best possible welding parameter set are determined by taking considerable effect to weld the Inconel 718 alloy in an effective and efficient manner. The selected objective functions are the bead width and depth of penetration were measured. Based on the design experiments were performed, and all the experimental data are submitted in Table 3.

Table 3 Layout of experiment using performance result and response surface

\begin{tabular}{llllll}
\hline \multirow{2}{*}{ Run } & Parameters & \multicolumn{3}{l}{ Experimental results } & DP \\
\cline { 2 - 6 } 1. & Iw & If & S & BW & 5.643 \\
\hline 2. & 1 & 1 & 3 & 3.987 & 6.325 \\
\hline 3. & 1 & 2 & 1 & 4.843 & 6.479 \\
\hline 4. & 1 & 2 & 3 & 5.356 & 7.358 \\
\hline 5. & 1 & 1 & 1 & 4.278 & 6.267 \\
\hline 6. & 1 & 2 & 2 & 4.257 & 6.564 \\
\hline 7. & 1 & 1 & 3 & 4.278 & 7.569 \\
\hline 8. & 1 & 3 & 1 & 4.825 & 7.168 \\
\hline 9. & 1 & 3 & 2 & 4.459 & 8.148 \\
\hline 10. & 1 & 3 & 3 & 5.710 & 7.893 \\
\hline 11. & 2 & 2 & 1 & 6.578 & 7.571 \\
\hline 12. & 2 & 2 & 2 & 5.170 & 6.452 \\
\hline 13. & 2 & 2 & 1 & 5.893 & 7.324 \\
\hline 14. & 2 & 1 & 3 & 5.109 & 7.931 \\
\hline 15. & 2 & 1 & 2 & 5.563 & 7.410 \\
\hline 16. & 2 & 2 & 3 & 5.645 & 7.640 \\
\hline 17. & 2 & 1 & 3 & 5.539 & 6.876 \\
\hline 18. & 3 & 3 & 2 & 4.674 & 7.412 \\
\hline 19. & 3 & 1 & 3 & 5.540
\end{tabular}




\begin{tabular}{llllll}
\hline \multirow{2}{*}{ Run } & Parameters & & \multicolumn{2}{l}{ Experimental results } \\
\cline { 2 - 6 } & Iw & If & S & BW & DP \\
\hline 20. & 3 & 1 & 2 & 5.356 & 7.785 \\
\hline 21. & 3 & 1 & 3 & 5.326 & 7.190 \\
\hline 22. & 3 & 2 & 1 & 5.258 & 7.692 \\
\hline 23. & 3 & 3 & 2 & 5.468 & 6.470 \\
\hline 24. & 3 & 2 & 3 & 5.368 & 6.843 \\
\hline 25. & 3 & 3 & 1 & 5.237 & 6.798 \\
\hline 26. & 3 & 1 & 2 & 5.569 & 7.114 \\
\hline 27. & 3 & 3 & 3 & 5.126 & \\
\hline
\end{tabular}

4.1Multiple response model result with GRA

The optimization problems are solved more effectively using GRA complicated optimization technique. The high value of Grey Relational Grade (GRG) provides improved multi response characteristics. The grade values are given at Table 4 for all experiments. Thus, it is evident that the experiment 4 provides better multi-response behaviour, such as bead width and Depth of Penetration with optimal parameters set [24].

Table 4 Normalised value of responses

\begin{tabular}{|c|c|c|c|}
\hline Exp. No. & Normalized values of BW & Normalized values of DP & Grade value \\
\hline 1 & 0.658703 & 0.474308 & 0.540898 \\
\hline 2 & 0.976109 & 1 & 0.977199 \\
\hline 3 & 0.863481 & 0.72332 & 0.714644 \\
\hline 4 & 0.843003 & 0.683794 & 0.686815 \\
\hline 5 & 0.887372 & 0.687747 & 0.715864 \\
\hline 6 & 0.511945 & 0.266798 & 0.455747 \\
\hline 7 & 0.552901 & 0.847826 & 0.647297 \\
\hline 8 & 0.733788 & 0.56917 & 0.594858 \\
\hline 9 & 0.389078 & 0.324111 & 0.437643 \\
\hline 10 & 0.979522 & 0.960474 & 0.943698 \\
\hline 11 & 0.535836 & 0.865613 & 0.653373 \\
\hline 12 & 0.40273 & 0.343874 & 0.444078 \\
\hline 13 & 0.412969 & 0.399209 & 0.457094 \\
\hline 14 & 0.648464 & 0.448617 & 0.531369 \\
\hline 15 & 0.505119 & 0.857708 & 0.640517 \\
\hline 16 & 0.351536 & 0.322134 & 0.42993 \\
\hline 17 & 0.764505 & 0.614625 & 0.622273 \\
\hline 18 & 0.679181 & 0.539526 & 0.564862 \\
\hline 19 & 0.40273 & 0.381423 & 0.451336 \\
\hline 20 & 1 & 0.960474 & 0.96337 \\
\hline 21 & 0.979522 & 0.956522 & 0.940328 \\
\hline 22 & 0.375427 & 0.385375 & 0.446597 \\
\hline 23 & 0.368601 & 0.409091 & 0.450132 \\
\hline 24 & 0.938567 & 0.954545 & 0.903622 \\
\hline 25 & 0 & 0 & 0.333333 \\
\hline 26 & 0.83959 & 0.958498 & 0.840232 \\
\hline 27 & 0.761092 & 0.511858 & 0.591337 \\
\hline
\end{tabular}

\subsection{GRG response}

The normalised value for the levels of welding inputs is depicted in Table 4. These values are estimated using the average of each level group at all process parameter levels. The grade of normalised value for BW is 0.96337 and grade of normalised value for DP is 0.977199 . The deformation formed in short duration with high heat inputs gives this variation in GRG. Table 5 shows the coefficient value of GRA. The grade of coefficient value for BW is 0.95975 and grade of normalised value for DP is 0.989127 . The heat inputs during EBW recrystallise the bonding of the materials gives the changes through input parameters [25]. 
Vishnu S et al.

Table 5 Grey relational coefficient and grey relational grade

\begin{tabular}{llll}
\hline Exp. No & coefficient of BW & Coefficient of DP & Grade value \\
\hline 1 & 0.594325 & 0.487476 & 0.540898 \\
\hline 2 & 0.948697 & 1 & 0.989127 \\
\hline 3 & 0.785523 & 0.643766 & 0.714644 \\
\hline 4 & 0.761039 & 0.612591 & 0.686815 \\
\hline 5 & 0.816156 & 0.615572 & 0.715864 \\
\hline 6 & 0.506045 & 0.405449 & 0.455747 \\
\hline 7 & 0.527928 & 0.766667 & 0.647297 \\
\hline 8 & 0.652561 & 0.537155 & 0.594858 \\
\hline 10 & 0.450077 & 0.42521 & 0.437643 \\
\hline 11 & 0.960656 & 0.92674 & 0.943698 \\
\hline 12 & 0.518584 & 0.788162 & 0.653373 \\
\hline 13 & 0.455677 & 0.432479 & 0.444078 \\
\hline 14 & 0.459969 & 0.454219 & 0.457094 \\
\hline 15 & 0.587174 & 0.475564 & 0.531369 \\
\hline 16 & 0.502573 & 0.778462 & 0.640517 \\
\hline 17 & 0.435364 & 0.424497 & 0.42993 \\
\hline 18 & 0.679814 & 0.564732 & 0.622273 \\
\hline 19 & 0.609148 & 0.520576 & 0.564862 \\
\hline 20 & 0.455677 & 0.446996 & 0.451336 \\
\hline 21 & 1 & 0.92519 & 0.95975 \\
\hline 22 & 0.960656 & 0.92 & 0.940328 \\
\hline 23 & 0.444613 & 0.448582 & 0.446597 \\
\hline 24 & 0.441931 & 0.458333 & 0.450132 \\
\hline 25 & 0.890578 & 0.916667 & 0.903622 \\
\hline 26 & 0.333333 & 0.333333 & 0.333333 \\
\hline 27 & 0.757106 & 0.923358 & 0.840232 \\
\hline & 0.676674 & 0.506 & 0.591337 \\
\hline
\end{tabular}

The major effect of plot of grey relation grade is presented in Figure 1. It represents the process parameters at optimal level, and the optimal process parameter set is $\mathrm{Iw}_{1} \mathrm{If}_{3} \mathrm{~S}_{1}$ that means the welding current of $60 \mathrm{~mA}$, focus current of $530 \mathrm{~mA}$ and welding speed of $22 \mathrm{~mm} / \mathrm{s}$. Welding speed acts as the major influencing factor, in addition to welding current and focus current. As it indicates the correlation level among the obtained order and reference order, the more data of standard grade value implies better relationship among them [26]. The plot shows the optimum level at $\operatorname{Iw}_{1} \mathrm{If}_{3} \mathrm{~S}_{1}$ and the input parameters are influenced with weld area. It is noted that grade value is decreased with welding current decreases continuously due to the relative distance of heat direction. But the grade effect is increases which focus current increases due to dense heat energy supplied at this level. When welding speed increases which decrease the grade effect due to the change in current effect from heat energy which affects the welding speed [27]. It is found from the plot that performance wise welding current is the influential parameter of EBW of Inconel 718 alloy.

1506
This means that high $\mathrm{S} / \mathrm{N}$ ratio corresponds to the optimal performance of EBW in predicting the level of process parameters.



Figure 1 Main effect plot of grey relation grade

\section{Discussion}

5.1Analysis of Variance in EBW parameters In this study a computation method used to estimate the involvement of variation in parameter created by whole reaction changes. It is utilized in the 
determination of the importance of parameters that acts as the input. The Minitab statistical software 14.0 is used in the evaluation of the importance of EBW parameters, like focus current and welding speed and welding current. To estimate optimal solution ANOVA is estimated using GRG to estimate the significance of process parameters [28]. From variance analysis, it was evident that the Welding current $(51.25 \%)$ has greater influence on the determination of the weld joint quality and the welding speed has $(4.6 \%)$ and focus current $(27.78 \%)$ are followed by the speed. The result of ANOVA depicts that the results are closely as similar to that of grey relational analysis, and Table 6 shows the outcomes of ANOVA. From analysis it is noted that welding current is most influential parameter in EBW of Inconel 718 alloy which has more percentage of $51.25 \%$. The second contribution to the analysis is welding speed with $27.78 \%$. ANOVA results displays P-value is 12.24 to the developed model for EBW and interferes the P-value which is significant [22].

Table 6 ANOVA Table

\begin{tabular}{llllll}
\hline List of factors & De & SS & MS & F & \% cont \\
\hline Welding current & 2 & 0.0457 & 0.055 & 12.24 & 51.25 \\
\hline Focus current & 2 & 0.0562 & 0.038 & 0.956 & 4.67 \\
\hline Welding speed & 2 & 0.0285 & 0.065 & 5.978 & 27.78 \\
\hline Error & 18 & 0.056 & 0.012 & NA & 16.30 \\
\hline Total & 24 & 0.168 & NA & NA & 100 \\
\hline
\end{tabular}

The contour output response due to the effect of EBW welding process parameters is shown in Figure 2 to Figure 4 respectively. From Figure 2 it is noted that for minimal welding current $63 \mathrm{~mA}$ and maximum focal current $533.5 \mathrm{~mA}$ gives high grade value due to the losses of thermal conductivity between the welds which decreases thermal efficiency. From Figure 3 it is noted that for minimum weld speed and minimum welding current give more grade value than maximum weld speed. This might be poor absorption of heat inside the gap of alloy [29]. It is observed from Figure 4 that more influencing parameter from minimum welding current and minimum weld speed. This is due to the effect of weld depth and also the material characteristics. With the increment of welding current up to $80 \mathrm{~mA}$ which increases the effect of $\mathrm{BW}$ and
DP. In lower input level heat energy is controlled with welding speed for the change in weld level.

Table 7 shows the outcomes of mean grey relational response grade. It is understood that the mean grey relation grade value is 0.45621 . The levels of process parameters are predicted as Iw1If $3 \mathrm{~S} 1$. This results leads to welding current as influential parameter in EBW. Based on the results for the input parameters, the ultimate section verifies the bead width in addition to the depth of penetration using confirmation experiments. From analysis Iw1If3S1 is the best parameter combination throughout EBW process by way of grey analysis [30]. In this section the reason for the change in response of output in case of experiment 10 and 21 with respect to some metallurgical characteristics, and the contour plots of GRG with respect to parameters are shown in figures and the actual and predicted value of GRG are shown in Figure 5. Figure 5 is represents the regression results which is close to the line. Hence the model is fit of developed mathematical model [30]. The exacting arrangement of input parameters is needed to accomplish the quality of welding conditions.

Preferring the favourable range EBW welding parameters were conversant, further steps to authorise the progress of the concert characteristics implementing the optimal association. Evaluation of the results involving the initial combination of the EBW welding parameters by executing the optimal one is detailed in Table 8. As perceived in Table 8, it is summarise the optimised conditions of confirmation experiment data. Is states that beam width goes up from $5.487 \mathrm{~mm}$ to $5.782 \mathrm{~mm}$ and depth of penetration value occurs from $7.367 \mathrm{~mm}$ to $7.458 \mathrm{~mm}$. The heat input through welding current gives the variation in the experimental values. As per outcomes noted, confirming that the quality uniqueness is supposed to be considerably enhanced via this authorization test [30]. Remarkable parameters and its percentage contribution gets modified similar to the parameter behaviour with unbiased response, while for every response Process parameters does not even experience a little effect but depth of penetration has a good effect on weld strength [31].

Table 7 Grey relational grade response table

\begin{tabular}{lllll}
\hline \multirow{2}{*}{ Factors } & \multicolumn{4}{c}{ GRG } \\
\cline { 2 - 5 } & L1 & L2 & L3 & Level \\
\hline $\mathrm{I}_{\mathrm{W}}$ & 0.5789 & 0.39862 & 0.51903 & 0.0962 \\
\hline
\end{tabular}


Vishnu S et al.

\begin{tabular}{lllll}
\hline \multirow{2}{*}{ Factors } & \multicolumn{4}{c}{ GRG } \\
\cline { 2 - 5 } & L1 & L2 & L3 & Level \\
\hline $\mathrm{I}_{\mathrm{F}}$ & 0.6289 & 0.62983 & 0.60372 & 0.0622 \\
\hline $\mathrm{S}$ & 0.4962 & 0.48294 & 0.45922 & 0.0238 \\
\hline \multicolumn{2}{l}{ Total mean of grey relational grade is 0.45621.} & &
\end{tabular}



Figure 2 Contour Plot of GRG vs Iw, If

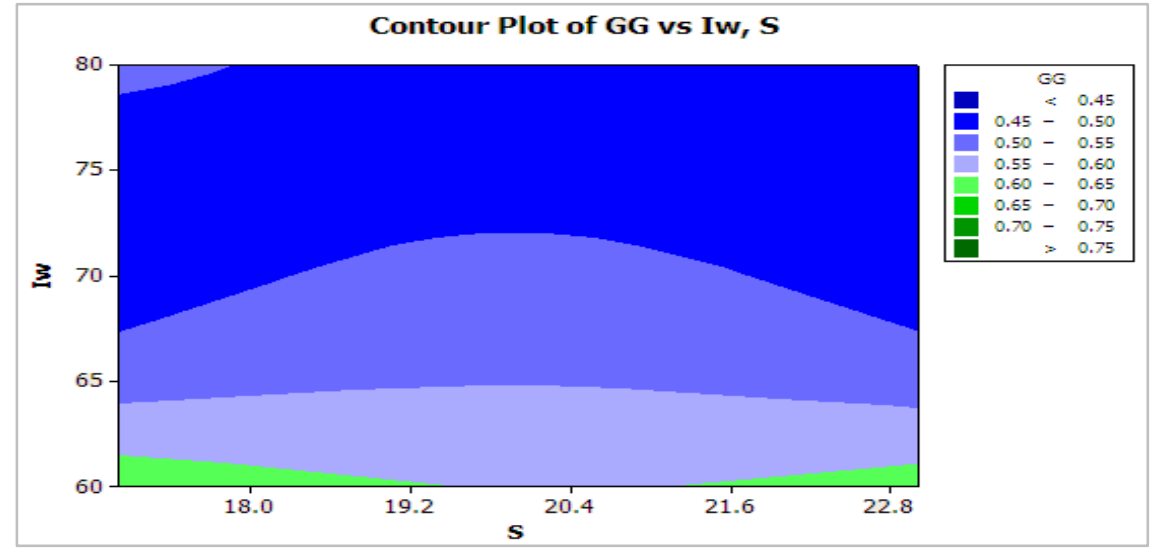

Figure 3 Contour Plot of GRG vs Iw, S

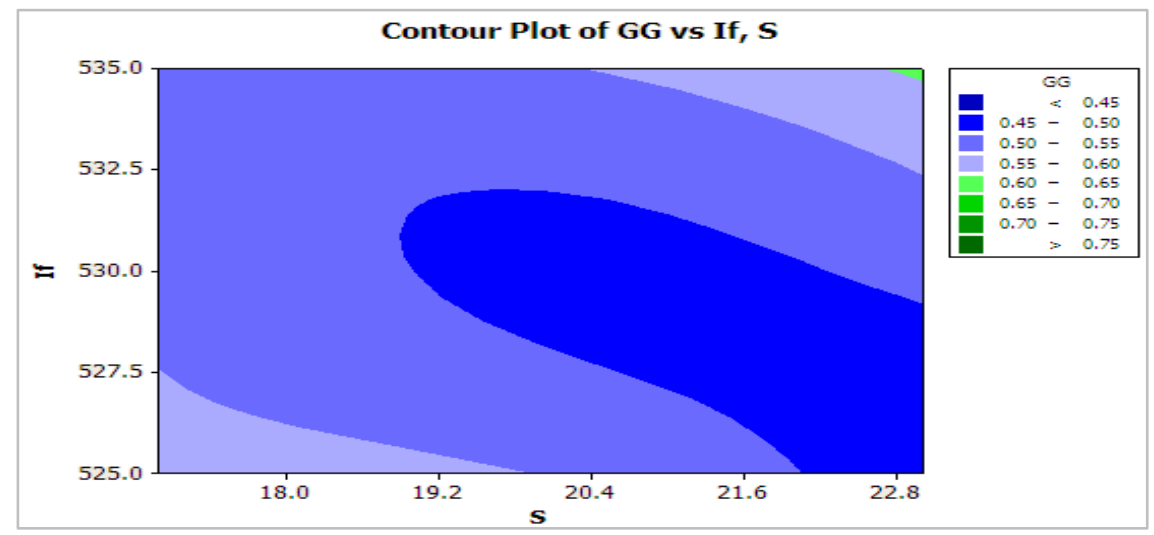

Figure 4 Contour Plot of GRG vs If, S 
Table 8 Validation of results against developed GRA model for EBW of Inconel 718 alloy

\begin{tabular}{llll}
\hline & Welding initial values & Predicted & Optimised conditions \\
\cline { 3 - 4 } Levels & $\mathrm{Iw}_{2} \mathrm{If}_{2} \mathrm{~S}_{2}$ & $\mathrm{Iw}_{1} \mathrm{If}_{3} \mathrm{~S}_{1}$ & Experiment \\
\hline Bead width & 5.487 & $\mathrm{NA}$ & 5.782 \\
\hline Depth of Penetration & 7.367 & $\mathrm{NA}$ & 7.458 \\
\hline Overall GRG & 0.487 & 0.546 & 0.578 \\
\hline Improvement in Grey Relational Grade 0.092 & & \\
\hline
\end{tabular}

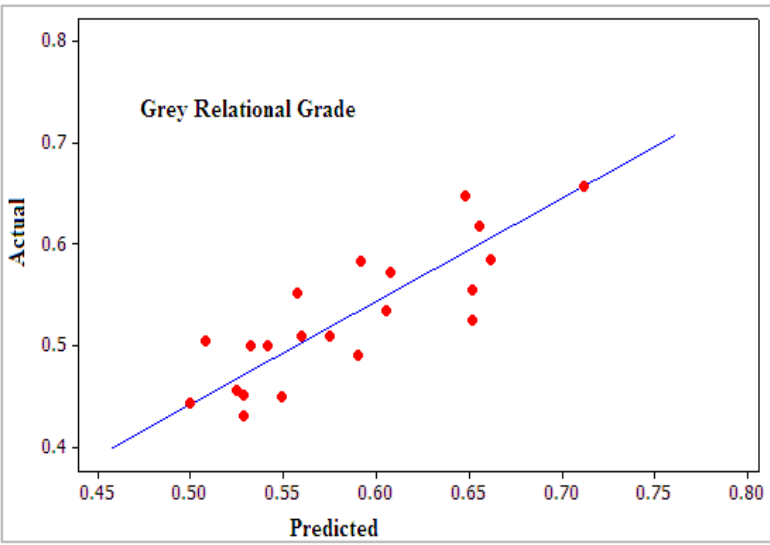

Figure 5 Plot of Actual vs Predicted results of GRG

\subsection{GA optimization}

The implementation as well the programming of the algorithm is always case dependant and adapts suitable platform. The fitness functions related to the issues in platform. Here the population is squared and is maintained low thus improving the search results. Finally convergence is arrived with the tuning of NSGA operators and count of generation characteristics. Figure 6 shows the convergence of NSGA for bead width and depth of penetration to obtain an optimized trend and the primary objective value attained while iteration [20]. The fitness function predicts that low depth of penetration with high bead width generates the optimal performance in EBW. It also give the details of the algorithms with efficiency in exploring through the solution space initially and converge to an immediate optimal or an optimal solution which seems to best in algorithm termination [21]. Multiple execution of the algorithm is done in making sure the outcomes repeatability. Table 9 presents the optimum performance of EBW process of Inconel 718 magnesium alloy with compared levels. It is reported from NSGA-II optimization results that maximum bead width is found at 4.235 and maximum depth of penetration is found at 7.341 and experiment results predicted that maximum bead width is found at 4.895 and maximum depth of penetration is found at 7.624. It is understood that $53.48 \%$ is improved enhancement in low heat welding and extends rupture life of the material [29]. As observed in Table 9 through the use of GA`s optimization technique, bead width increases from 4.235 to 4.895 for NSGA-II algorithm and depth of penetration increased from 7.341 to 7.624 for NSGA-II algorithm. Depending up on the specified solutions, the quality characteristics that are highly enhanced by the use of GA optimization technique is clearly noticed [32].

Table 9 Optimized parameters value

\begin{tabular}{llllll}
\hline Method & Iw & If & S & BW & DP \\
\hline NSGA-II & 70 & 530 & 22 & 4.235 & 7.341 \\
\hline Experiment & 70 & 530 & 23 & 4.895 & 7.624 \\
\hline
\end{tabular}

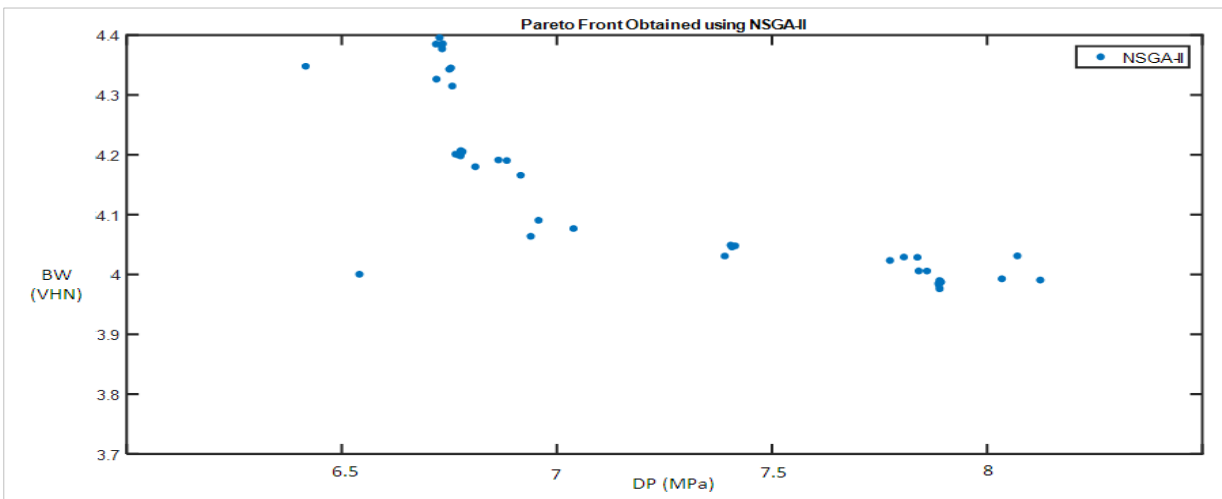

Figure 6 Fitness function plot for EBW process using NSGA II (GA) 


\subsection{Validation test}

To validate the experimental results with optimized values of electron beam weld parameters confirmatory test is conducted to attain concentrated weld quality based on Table 8 . The outcome of table presents the comparison of experimental and optimized results. It is clear to understand that there is good improvement in optimized results from 7.321 $\mathrm{mm}$ to $7.624 \mathrm{~mm}$. Validation experiment has been done with fractography analysis [33]. Microstructure observation is taken in welded pieces for the analysis of weld deposition that is present on the weld zone is shown in Figure 7 (a-b). From Figure 7 (a) and (b) shows the heavy flow of material in sliding side and it causes wear between tool and material [34]. These images help to study the ductility of welded samples. It is noted that minimum brittle area and lower brittle place are found in the samples. This is due to weld side allows more temperature the materials to interface easily to get bonding and improves the strength of joining [35]. Figure 7 (b) illustrates the bead weld position initiates cracks and disseminated inside the weld sample. These results give details of the fact of low ductility of weld samples.

\subsection{Limitations}

As per experimental analysis the comparative analysis through GA and grey analysis were acceptable. But there are few limitations to overcome. In welding chamber the size of material is to be altered during experimental conditions. Due to rapid cooling cracks may be produced in some samples. Few welded samples were fractured due to high level heat inputs.

A complete list of abbreviations is shown in Appendix I.

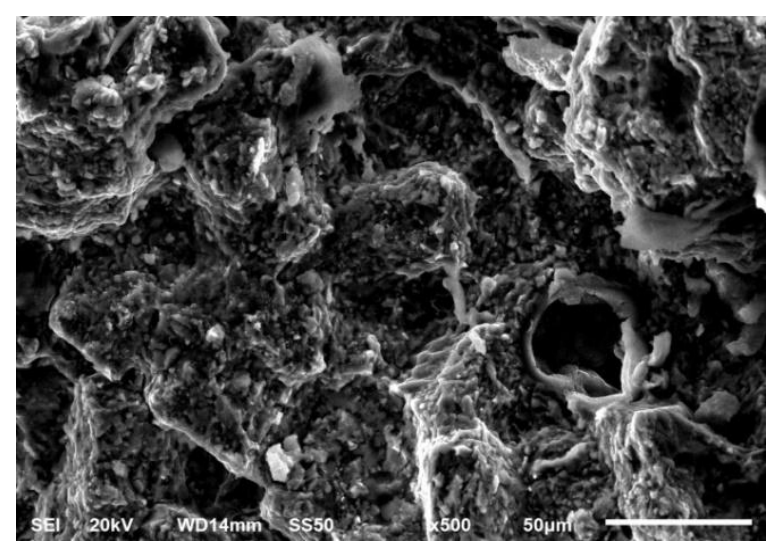

Figure 7(a) SEM image at $\mathrm{Iw}=60 \mathrm{~mA}$, If $=530 \mathrm{~mA}$ (500x)

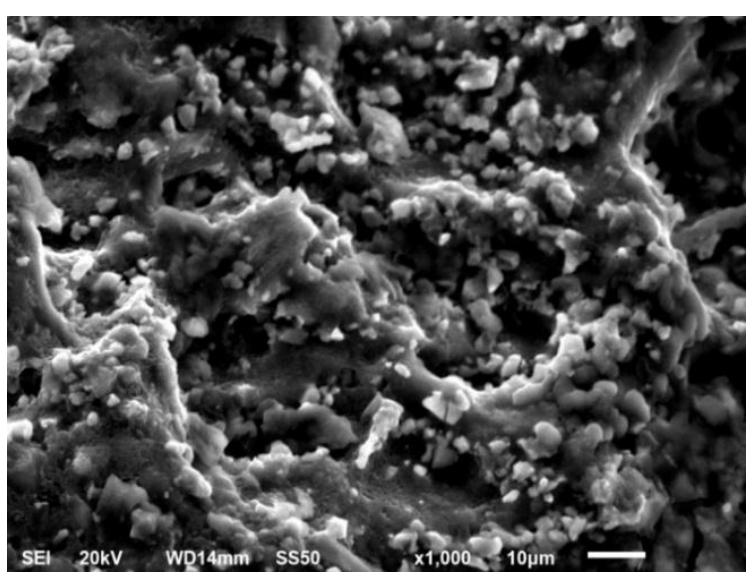

Figure 7(b) SEM image at $\mathrm{Iw}=60 \mathrm{~mA}$, Speed $=23$ $\mathrm{mm} / \mathrm{s}(1 \mathrm{Kx})$

\section{Conclusion and future work}

In order to optimize the multiple performance behaviours, namely hardness and tensile strength, the response surface method Box Behnken design in the presence of genetic algorithm is done in this study. The optimal welding parameters for minimum Bead Width was found to be Iw1If3S2 and for maximum Depth of Penetration was Iw2If3S1. But the optimal conditions for both the effects were found out from the $\mathrm{S} / \mathrm{N}$ graph of Grey Relational Grade as Iw2If2S3. The Proposed and developed EBW results were compared with GRA and GA algorithms. Results show the validation of results against developed GRA and GA models. The optimal results indicated that bead width is 4.8 and depth of penetration is 7.6 for the process parameters at $70 \mathrm{~mA}, 530 \mathrm{~mA}$, and $23 \mathrm{~mm} / \mathrm{s}$ respectively. On the basis of the results of ANOVA of GRG, it was noted with the welding current of $(68 \%)$ that created a considerable effect on multiple responses with the focus current of (13\%) and welding speed of $(9 \%)$. Results validate that GA model gives optimal results than GRA model. The reason is that GA looks solution in the search space not quite the same as GRA. The impact fractography test indicated ductile mode fracture in case of experiment 6 and mixed brittle and ductile modes of fracture in case of experiment 12. In weld region microstructure showed better cellular structure in case of experiment 6 , whereas harder dendrites were created in case of experiment 12 because of high heat input. The future work of the research is some concepts shall be used to model the experiments using neural network and predict the error analysis in order to evaluate the accuracy of modelling. Automation in welding parameters in EBW and welding of Inconel 718 with other materials is still a challenge and a great scope for research. 
Acknowledgment

None.

\section{Conflicts of interest}

The authors have no conflicts of interest to declare.

\section{References}

[1] Sonar T, Balasubramanian V, Malarvizhi S, Venkateswaran T, Sivakumar D. An overview on welding of inconel 718 alloy-effect of welding processes on microstructural evolution and mechanical properties of joints. Materials Characterization. 2021.

[2] Sharma SK, Biswas K, Majumdar JD. Effect of heat input on mechanical and electrochemical properties of electron-beam-welded inconel 718. Journal of Materials Engineering and Performance. 2020; 29(3):1706-14.

[3] Patel V, Sali A, Hyder J, Corliss M, Hyder D, Hung W. Electron beam welding of inconel 718. Procedia Manufacturing. 2020; 48:428-35.

[4] Vora JJ, Abhishek K, Ramkumar PL. Different methodologies for the parametric optimization of welding processes. In advances in welding technologies for process development 2019 (pp. 5575). CRC Press.

[5] Shrivastava PK, Norkey G, Pandey AK. Optimization of process parameters during the laser cutting of inconel-718 sheet using regression based genetic algorithm. Materials Today: Proceedings. 2019; 18:A17-25.

[6] Sharma SK, Biswas K, Majumdar JD. Studies on electron beam surface remelted inconel 718 superalloy. Metals and Materials International. 2020; 27:5360-73.

[7] Halsey W, Ferguson J, Plotkowski A, Dehoff R, Paquit V. Geometry-independent microstructure optimization for electron beam powder bed fusion additive manufacturing. Additive Manufacturing. 2020.

[8] Bal KS, Majumdar JD, Choudhury AR. Optimization of melt zone area for electron beam welded hastelloy C-276 sheet and study of corrosion resistance of the optimized melt zone in $3.5 \mathrm{wt} \% \mathrm{NaCl}$ aqueous solution. Arabian Journal for Science and Engineering. 2019; 44(2):1617-30.

[9] Choudhury B, Chandrasekaran M. Electron beam welding of aerospace alloy (Inconel 825): a comparative study of RSM and ANN modeling to predict weld bead area. Optik. 2020.

[10] Shrivastava PK, Singh B, Shrivastava Y. Prediction of optimal cut quality characteristic of inconel 718 sheet by genetic algorithm and particle swarm optimization. Journal of Laser Applications. 2019; 31(2).

[11] Vagheesan S, Govindarajalu J. Hybrid neural network-particle swarm optimization algorithm and neural network-genetic algorithm for the optimization of quality characteristics during $\mathrm{CO} 2$ laser cutting of aluminium alloy. Journal of the Brazilian Society of Mechanical Sciences and Engineering. 2019; 41(8):15.
[12] Ramanan G, Dhas JE. Multi objective optimization of wire EDM machining parameters for AA7075-PAC composite using grey-fuzzy technique. Materials Today: Proceedings. 2018; 5(2):8280-9.

[13] Ghosh G, Mandal P, Mondal SC. Modeling and optimization of surface roughness in keyway milling using ANN, genetic algorithm, and particle swarm optimization. The International Journal of Advanced Manufacturing Technology. 2019; 100(5):1223-42.

[14] Sokkalingam R, Mastanaiah P, Muthupandi V, Sivaprasad K, Prashanth KG. Electron-beam welding of high-entropy alloy and stainless steel: microstructure and mechanical properties. Materials and Manufacturing Processes. 2020; 35(16):1885-94.

[15] Taguchijeve UG, FSW VT. Application of grey relation analysis (GRA) and taguchi method for the parametric optimization of friction stir welding (FSW) process. Materials and Technology. 2010; 44:205-11.

[16] Niu H, Jiang HC, Zhao MJ, Rong LJ. Effect of interlayer addition on microstructure and mechanical properties of $\mathrm{NiTi} /$ stainless steel joint by electron beam welding. Journal of Materials Science \& Technology. 2021; 61:16-24.

[17] Liu X, Dong Q, Wang P, Chen H. Review of electron beam welding technology in space environment. Optik. 2021.

[18] Shen X, Gao K, Dong S. Simulation and analysis of electron beam welding residual stress in thin-walled high-temperature alloy aeroengine structures. The International Journal of Advanced Manufacturing Technology. 2020; 107(9):3953-66.

[19] Raja R, Jannet S, Ruban SR. Mechanical and metallurgical studies of multi-walled carbon nanotube-reinforced aluminium metal matrix surface composite by friction stir processing. International Journal of Advanced Technology and Engineering Exploration. 2021; 8(78):643-50.

[20] Chahar R, Kaur D. A systematic review of the machine learning algorithms for the computational analysis in different domains. International Journal of Advanced Technology and Engineering Exploration. 2020; 7(71):147-64.

[21] Javid Y. Multi-response optimization in laser cladding process of WC powder on inconel 718. CIRP Journal of Manufacturing Science and Technology. 2020; 31:406-17.

[22] Bodukuri AK, Kesha E. Multi-attribute optimization of EDM process parameters for machining of $\mathrm{SiC}$ and $\mathrm{B} 4 \mathrm{C}$ particle reinforced $\mathrm{Al} 6061$ metal matrix composite adopting TOPSIS method. International Journal of Advanced Technology and Engineering Exploration. 2021; 8(79):735-52.

[23] Pandiyarajan R. Improving mechanical strength on welded joints by using optimisation technique. International Journal of Enterprise Network Management. 2021; 12(1):85-96.

[24] Bakhtiyari AN, Wang Z, Wang L, Zheng H. A review on applications of artificial intelligence in modeling and optimization of laser beam machining. Optics \& Laser Technology. 2021. 
[25] Rajamani D, Siva KM, Balasubramanian E, Tamilarasan A. Nd: YAG laser cutting of hastelloy C276: ANFIS modeling and optimization through WOA. Materials and Manufacturing Processes. 2021; 36(15):1746-60.

[26] Choudhury B, Chandrasekaran M. Microstructural investigation and integrated optimization of weld bead characteristics in electron beam welding of inconel 825. Transactions of the Indian Institute of Metals. 2021; 74:2681-2701.

[27] Sali AR, Patel V, Hyder J, Hyder D, Corliss M, Hung $\mathrm{W}$. Electron-beam welding of laser powder-bed-fused inconel 718. International Journal of Engineering Materials and Manufacture. 2021; 6(3):209-24.

[28] Kovař́iková I, Šimeková B, Urminský J, Kovačócy P, Hodúlová E. Experimental study of electron beam welding of inconel alloy. In vehicle and automotive engineering 2020 (pp. 517-25). Springer, Singapore.

[29] Raute J, Jokisch T, Marko A, Biegler M, Rethmeier $\mathrm{M}$. Influence of electron beam welding parameters on the weld seam geometry of inconel 718 at low feed rates. Materials Testing. 2020; 62(12):1221-7.

[30] Jia S, Li D, Tao F, Fan L, Chen J. Effects of the beam offset on microstructure and properties of electron beam welded tantalum and inconel 718 joints. Materials Research Express. 2021; 8(4):1-14.

[31] Zhang G, Chen G, Cao H, Yin Q, Zhang B. Crack generation mechanism and control method of electron beam welded Nb/GH3128 joint. Journal of Materials Processing Technology. 2022.

[32] Tsonevska TS, Koleva EG, Koleva LS, Mladenov GM. Modelling the shape of electron beam welding joints by neural networks. In journal of physics: conference series 2018 (pp. 012008). IOP Publishing.

[33] Xu D, Wang H, Tao X, Yao Z, Zhang S, Oleksander $M$. Investigation on microstructure, hardness and wear resistance of electron beam wire-feeding deposited inconel 718 alloy coatings. Metals and Materials International. 2021; 27(5):1263-72.

[34] Sonar T, Balasubramanian V, Malarvizhi S, Venkateswaran T, Sivakumar D. Microstructural evolution and grain refinement in gas tungsten constricted Arc (GTCA) welds of inconel 718 alloymechanism and segregation analysis. Physics of Metals and Metallography. 2021:1-9.

[35] Lin J, Wang X, Lei Y, Wei R, Guo F. Study on hot cracking in laser welded joints of inconel 718 alloy foils. Journal of Manufacturing Processes. 2021; 64:1024-35.

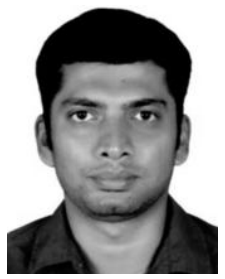

Mr. S. Vishnu, Scholar, in Mechanical Engineering at Noorul Islam Centre for Higher Education, Kumaracoil. He did his master's at the National Engineering College, Kovilpatti, Tamilnadu, India. Currently he is perusing his Ph.D. at Noorul Islam Centre for Higher Education, Kumarcoil, Tamilnadu.

Email: vishnusanjiv@gmail.com



Dr. Satheesh $\mathbf{M}$ is Professor in the Department of Mechanical Engineering at Noorul Islam Centre for Higher Education. $\mathrm{He}$ has published 30 International journal papers in various journals. His research interests are Modelling, Simulation and Analysis and Optimization of Manufacturing

Systems.

Email: satheeshudaya@gmail.com



Edwin Raja Dhas is a Professor and Head in the Department of Automobile Engineering at Noorul Islam Centre for Higher Education, Tamil Nadu, India. He obtained his Doctoral Degree from National Institute of Technology, Tiruchirappalli, India. His research interests are Nontraditional Simulation and Optimization of Manufacturing Systems. He has published more than hundred technical articles in International and National Journals. He is the Life member of Indian Welding Society.

Email: edwinrajadhas@ rediffmail.com

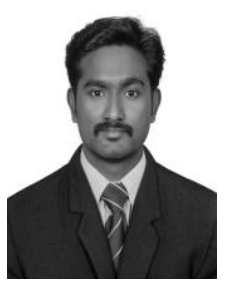

Dr. Ramanan $\mathbf{G}$ is an Associate Professor at ACS College of Engineering, Bangalore. He obtained his Ph.D in Aeronautical Technology from Noorul Islam Centre for Higher Education, Kumaracoil and Masters in Aerospace Technology from Madras Institute of Technology, Chennai. He possesses twelve years of teaching and research experience and published many research papers in International and National journals and conferences. His current research projects focus on Materials Characterization, Advanced Manufacturing Process to the highly relevant applications to the Aerospace Technology.

Email: ramanangaero@gmail.com 


\begin{tabular}{lll}
\multicolumn{2}{l}{ Appendix 1 } \\
\hline S. No. & Abbreviation & Description \\
\hline 1 & ANOVA & Analysis of Variance \\
\hline 2 & BW & Bead Width \\
\hline & Deg & Degree \\
\hline 3 & DP & Depth of penetration \\
\hline & DOE & Design of Experiments \\
\hline 4 & EBW & Electron Beam Welding \\
\hline 6 & GA & Genetic Algorithm \\
\hline 7 & GRA & Grey Relational Analysis \\
\hline 8 & GRC & Grey Relational Coefficient \\
\hline 9 & GRG & Grey Relational Grade \\
\hline 10 & Max & Maximum \\
\hline 11 & MS & Minimum \\
\hline 12 & mm/s & Mean Squares \\
\hline 13 & mA & Millimeters per Second \\
\hline 14 & NSGA-II & $\begin{array}{l}\text { Non dominated Sorting Genetic } \\
\end{array}$ \\
\hline 15 & PSO & Algorithm-II \\
\hline 16 & RSM & Response Surface Methodology \\
\hline 17 & S/N & Signal to Noise Ratio \\
\hline 18 & SS & Sum of Squares \\
\hline
\end{tabular}

